\title{
TRANSTORNO DO DÉFICIT DE ATENÇÃO / HIPE- RATIVIDADE EM CRIANÇAS EM IDADE ESCOLAR
}

\section{ATTENTION DEFICIT / HYPERACTIVITY DISOR- DER IN SCHOOL-AGE CHILDREN}

\author{
Raquel Elisiane Jardim Paz ${ }^{1}$ \\ Lisiane França Garcia Franquilin ${ }^{2}$
}

Resumo: O Transtorno do Défipodem contribuir para que esse cit de Atenção / Hiperatividade aluno possa ter aprendizagens é uma tríade comportamental na significativas - além do olhar criança caracterizada por: distraatento do professor e sua conção, impulsividade e hiperatividuta afetuosa. Apesar do Transdade, trazendo sérios prejuízos torno do Déficit de Atenção ser sociais e de aprendizagens a seus reconhecido oficialmente pela portadores. Atualmente há trataOrganização Mundial da Saúde mentos medicamentosos e tera(OMS) e por diversos países, e pêuticos que vem auxiliar crianestar no Manual diagnóstico e ças com TDAH a desenvolver estatístico de transtornos mensuas habilidades e assim, melhotais: DSM-5; no Brasil ainda não rar sua auto-estima. A família e encontram-se leis específicas em a escola andando juntas também âmbito federal, para alunos com

\footnotetext{
1 IERGS

2 Professora. Licenciada em Pedagogia com Habilitação em Supervisão Escolar e Matérias Pedagógicas do Ensino Médio. Psicopedagoga Clínica e Institucional. Especialista em Neuropsicopedagogia. Mestra em Educação (UFRGS)
}

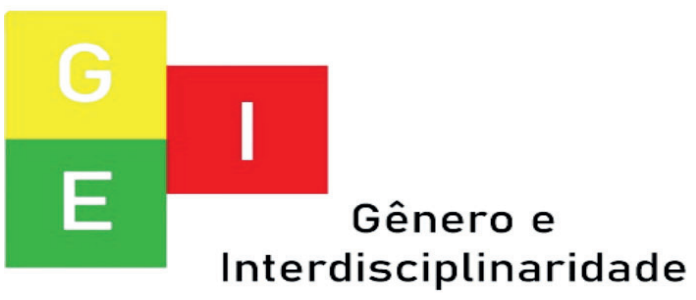


ISSN: 2675-7451

Vol. 02 - n 05 - ano 2021

Editora Acadêmica Periodicojs

esse transtorno.

the World Health Organization

(OMS) and by several countries,

Palavras-chave: Transtorno do and is included in the Diagnostic

Déficit de Atenção / Hiperativiand Statistical Manual of Mendade. Crianças. Aprendizagens Significativas.

tal Disorders: DSM-5; in Brazil there are still no specific laws at the federal level for students with

Abstract: Attention Deficit / this disorder.

Hyperactivity Disorder is a behavioral triad in children characterized by: distraction, impulsivity and hyperactivity, bringing serious social and learning losses to its carriers. Currently, there are drug and therapeutic treatments that help children with ADHD to develop their skills and thus improve their self-esteem. The family and the school walking together can also contribute so that this student can have meaningful learnings - in addition to the attentive look of the teacher and his affectionate conduct. Although Attention Deficit Disorder is officially recognized by

\author{
Keywords: Attention Deficit / \\ Hyperactivity Disorder. Chil- \\ dren. Significant Learning.

\section{INTRODUÇÃO} \\ $\mathrm{O}$ assunto apresentado
} neste artigo será sobre Transtorno do Déficit de Atenção / Hiperatividade - TDAH, em crianças em idade escolar.

Compreender suas causas e origens, se o ambiente favorece o surgimento deste transtorno ou se existe algum componente químico, genético

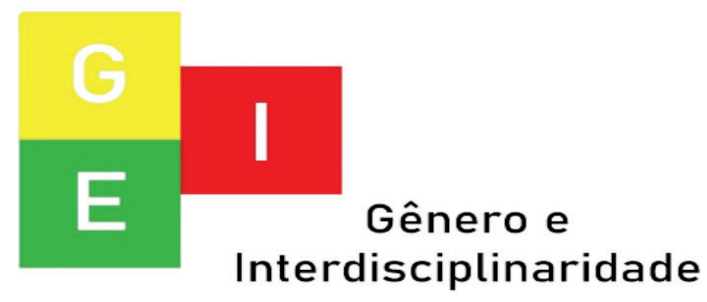


ISSN: $2675-7451$

Vol. 02 - n 05 - ano 2021

Editora Acadêmica Periodicojs

ou lesão, que contribui para o sur-

gimento desses sintomas; e como

é o funcionamento desse cérebro

- se apresenta alguma diferença

em sua estrutura e se há perdas

intelectuais aos seus portadores.

Inicialmente se aborda-

rá o que é esse transtorno e seus

principais sintomas, as causas e os tratamentos atualmente dispo-

níveis, analisaremos o papel da família e da escola e suas contribuições com a aprendizagem nessa necessidade educacional especial; destacaremos as leis que regem o direito a educação desta necessidade educacional especial e a importância deste direito.

O QUE É O TDAH, QUAIS SÃO SEUS SINTOMAS E SUAS CAUSAS ${ }^{1}$

1 Transtorno de Déficit de Atenção / Hiperatividade com as siglas: TDAH ou TDA, de
No decorrer deste artigo vamos nos referir também ao Transtorno de Déficit de Atenção / Hiperatividade com a sigla: TDAH3. Porém, o que seria o Transtorno de Défict de Atenção e Hiperatividade? De acordo com o DSM-5 (2014, grifos meus) “O TDAH é um transtorno do neurodesenvolvimento definido por níveis prejudiciais de desatenção, desorganização e/ou hiperatividade-impulsividade, que interfere no funcionamento ou no desenvolvimento.” A ABDA Associação Brasileira do Déficit de Atenção nos diz: "é um transtorno neurobiológico, de causas genéticas, que aparece na infância e freqüentemente acompanha o indivíduo por toda a sua vida. Ele se caracteriza por sintomas acordo como cada autor citado expõe, no entanto, estaremos nos referindo ao mesmo transtorno.

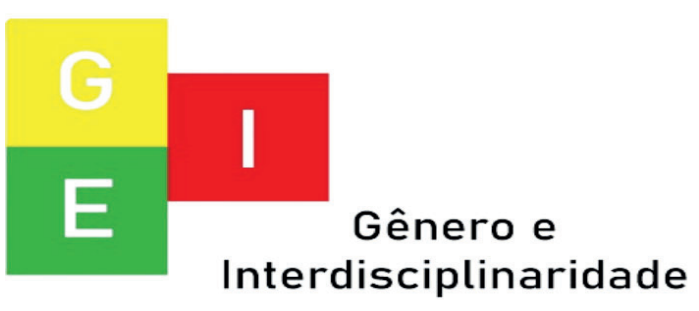


ISSN: 2675-7451

Vol. 02 - n 05 - ano 2021

Editora Acadêmica Periodicojs

de desatenção, inquietude e impulsividade."

Em conformidade Ana Beatriz destaca essa tríade de comportamento no indivíduo que caracteriza as diferentes maneiras de se manifestar:

O comportamento TDA nasce do que se chama trio de base alterada. É com base nesse trio de sintomas - formado por alterações da atenção, da impulsividade e da velocidade da atividade física $\mathrm{e}$ mental - que se desvendará todo o universo TDA, o qual, muitas vezes, oscila entre a plenitude criativa e a exaustão de um cérebro que não para nunca. (SILVA, 2014, p. 23)

Abaixo vamos discorrer de forma breve cada uma dessas características e seus sintomas.

\section{Alteração da atenção:}

Conforme o DSM-5 (2014, p.61) "a desatenção manifesta-se comportamentalmente no TDAH como divagação em tarefas, falta de persistência, dificuldade de manter o foco e desorganização - e não constitui consequência de desafio ou falta de compreensão."

Como vimos o déficit de atenção ou alteração da atenção é uma dificuldade em manter a concentração, e esse é o sintoma que mais se manifesta no entendimento TDAH, segundo Silva (2014, p.24) "uma pessoa com comportamento TDA pode ou não apresentar hiperatividade física, mas jamais deixará de apresentar forte tendência à dispersão."

\section{Impulsividade:}

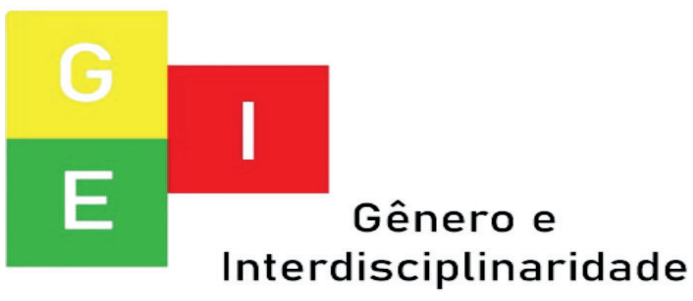


ISSN: $2675-7451$

Vol. 02 - n 05 - ano 2021

Editora Acadêmica Periodicojs

A impulsividade se ca- "hiperatividade mental ou psíracteriza pela falta de autocontroquica apresenta-se de maneira le, agir sem reflexão, sem se premais sutil, o que não significa em ocupar com as consequências, ou hipótese alguma, que seja menos seja, "a impulsividade refere-se a penosa que sua irmã física”. (SILações precipitadas que ocorrem VA, 2014, p. 32)

no momento sem premeditação e com elevado potencial para dano à pessoa (p. ex., atravessar uma rua sem olhar)." (DSM-5, 2014, p.61)

\section{CAUSAS}

No tópico anterior vimos o que é o TDAH, a seguir vamos compreender suas causas Hiperatividade Física / Mental: e origens, se o ambiente favorece o surgimento deste transtorno

Sobre a Hiperatividade Física é a elevação da função motriz, que "significa inquietação motora excessiva e agressiva, não apenas espasmos de nervosismo [...] é como se estivesse sempre ligados na tomada ou "Ele parece movido à pilha." (PHELAN, 2005, p. 24)

A Hiperatividade Mental é uma intensa inquietação mental, conforme Ana Beatriz ou se existe algum componente químico, genético ou lesão, que contribui para o surgimento desses sintomas; e como é o funcionamento desse cérebro - se apresenta alguma diferença em sua estrutura e se há perdas intelectuais aos seus portadores.

Ana Beatriz aponta o TDAH de causas genéticas e orgânica:

O TDA é um funcio-

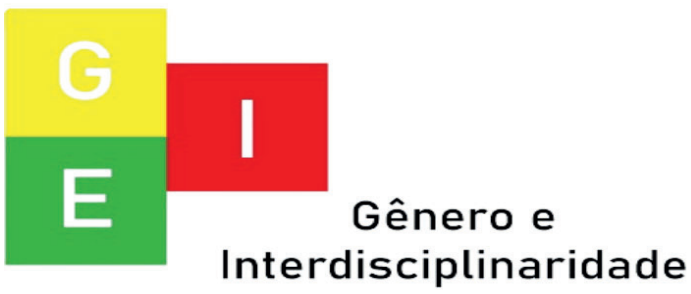


ISSN: 2675-7451

Vol. 02 - n 05 - ano 2021

Editora Acadêmica Periodicojs

namento de origem biológica, marcado pela herança genética, que se manifesta na criança ainda bem jovem, antes dos sete anos, independente de ela ser proveniente de um ambiente hostil ou de estar passando por problemas. Mesmo nos lares estruturados e seguros, uma criança TDA se comportará como tal. (SILVA, 2014, p. 73, grifos meus)

Nessa mesma linha a Associação Brasileira do Déficit de Atenção, afirma que independente dos fatores ambientais em que vive essa criança, o ambiente não determina o surgimento desse transtorno:

Já existem inúmeros estudos em todo o mundo - inclusive no Brasil - demonstrando que a prevalência do TDAH é semelhante em dife- rentes regiões, o que indica que o transtorno não é secundário a fatores culturais (as práticas de determinada sociedade, etc.), o modo como os pais educam os filhos ou resultado de conflitos psicológicos. (ABDA - Associação Brasileira do Déficit de Atenção, 09/02/2017)

Podemos afirmar que os TDAHs apresentam alguma deficiência intelectual ou alguma falta de inteligência? De acordo com Silva (2014 p. 75) "esse comportamento diferenciado não tem nenhuma relação com déficit intelectual. Na verdade, com extrema freqüência, a criança TDA é bastante inteligente e criativa." Mas o cérebro dessa criança é diferente das crianças não TDAHs? Como podemos entender isso? Silva (2014, p.233)

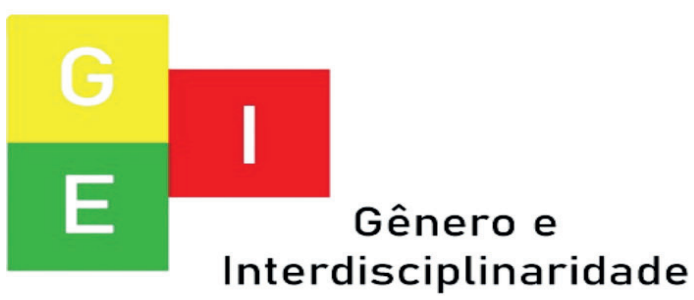


ISSN: 2675-7451

Vol. 02 - n 05 - ano 2021

Editora Acadêmica Periodicojs

nos esclarece: "o cérebro de um TDA, em forma e aparência, em nada difere do cérebro que não apresenta um funcionamento TDA; a diferença está no íntimo dos circuitos cerebrais movidos e organizados pelos neurotransmissores."

Vimos que o cérebro em sua estrutura em nada se distingue dos demais, a diferença está na atividade química desse cérebro não ser tão eficaz, a ABDA Associação Brasileira do Déficit de Atenção (2010), nos fala,

$\mathrm{O}$ que parece estar alterado nesta região cerebral é o funcionamento de um sistema de substâncias químicas chamadas neurotransmissores (principalmente dopamina e noradrenalina), que passam informação entre as células nervosas (neurônios). Existem causas que foram investigadas para estas alterações nos neurotransmissores da região frontal e suas conexões.

Essas alterações desses neurotransmissores na região frontal do cérebro é o causador dos sintomas que caracterizam o TDAH: desatenção, impulsividade e hiperatividade,

Estudos científicos mostram que portadores de TDAH têm alterações na região frontal e as suas conexões com o resto do cérebro. A região frontal orbital é uma das mais desenvolvidas no ser humano em comparação com outras espécies animais e é responsável pela inibição do comportamento (isto é, controlar ou inibir comportamentos inadequados), pela capacidade de prestar

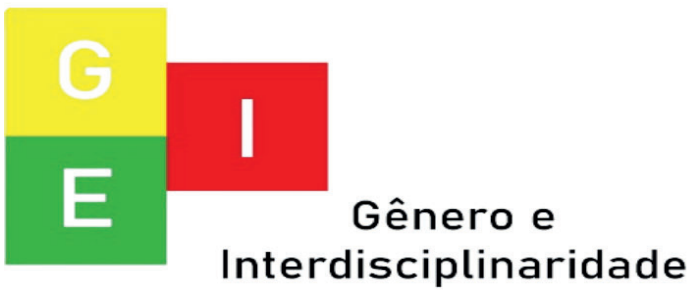


ISSN: 2675-7451

Vol. 02 - n 05 - ano 2021

Editora Acadêmica Periodicojs

atenção, memória, responsáveis pelas autocontrole, organização e planejamento. (ABDA - Associação Brasileira do Déficit de Atenção, 09/02/2017)

Ana Beatriz também nos esclarece sobre o funcionamento desse cérebro TDAH, e nos deixa claro que esse desempenho não muito eficiente dessa química, não tem nada a ver com alguma lesão e sim uma disfunção:

O transtorno do déficit de atenção deriva de um funcionamento alterado no sistema neurobiológico cerebral. Isso significa que substâncias químicas produzidas pelo cérebro, chamadas neurotransmissores, apresentam alteradas quantitativa e/ou qualitativamente no interior dos sistemas cerebrais

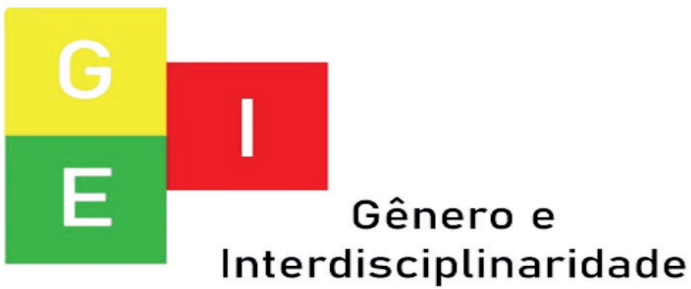
ção ocorre o mesmo processo: sem um filtro eficiente, a mente TDA é invadida por uma avalanche de estímulos que acabam por desviar seu foco atentivo a todo instante. Por isso tudo é que costumo dizer que o cérebro TDA anda a duzentos por hora, enquanto os de- 
Vol. 02 - n 05 - ano 2021

Editora Acadêmica Periodicojs

mais se mantém a oitenta. (SILVA, 2014, p. 125)

\section{TRATAMENTOS}

A seguir vamos comentar sobre os tratamentos disponíveis atualmente para amenizar os sintomas TDAHs e ajudar a criança a desenvolver suas habilidades, e assim, melhorar sua auto-estima.

Estudos cada vez mais aprofundados e específicos sobre o TDAH desvendam novas técnicas de enfrentamento para esta problemática, novos recursos psicoterapêuticos e medicamentosos, com a finalidade de que haja uma diminuição da interferência que os sintomas do TDAH causam na vida da pessoa, fazendo com que esta consiga aumentar a concentração e controlar a hiperatividade e a impulsividade. (ABDA - Associação Brasileira do Déficit de Atenção, 2016)

Ana Beatriz divide o tratamento em quatro etapas fundamentais para que haja um bom resultado no comportamento, "costumo dividir o tratamento do TDA em quatro grandes etapas: informação/conhecimento, apoio técnico, terapêutica medicamentosa e psicoterapia." (SILVA, 2014, p. 257)

Os medicamentos comprovadamente costumam ajudar bastante para a melhora dos sintomas do transtorno, é o que afirma a ABDA - Associação Brasileira do Déficit de Atenção (2016):

A prescrição de medicamentos psicotrópicos é o tratamento mais comum para

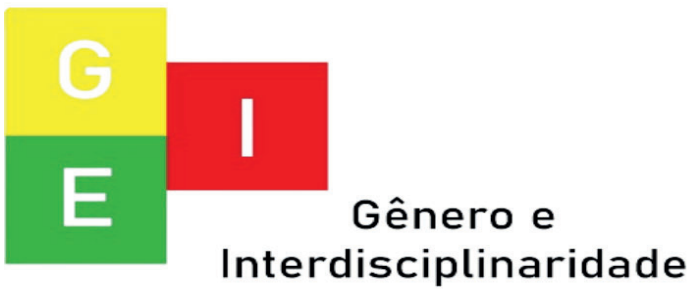


Vol. 02 - n 05 - ano 2021

Editora Acadêmica Periodicojs

o TDAH. Numerosos estudos têm demonstrado, de modo coerente, a rápida melhora do funcionamento comportamental, acadêmico e social da maioria das crianças tratadas com substâncias estimulantes. São chamados assim em virtude de sua capacidade comprovada de aumentar a excitação ou "alerta" do sistema nervoso central.

Ainda de acordo com a Associação Brasileira do Déficit de Atenção, esses medicamentos não curam, mas, a forma como esses agem no organismo dos TDAHs ajudam diminuir os sintomas durante o seu uso, com benefício de não causar dependência.

Estas medicações melhoram extraordinariamente a capacidade motora da pessoa de colocar seus pensamentos no papel, aprimoram a atenção e a impulsividade, aumentam a motivação e a concentração, com a vantagem de não provocar dependência nos usuários. Esses medicamentos não curam o TDAH, mas ajudam a normalizar os neurotransmissores durante o seu uso. Dessa forma, diminui as consequências negativas emocionais, acadêmicas e sociais. (ABDA - Associação Brasileira do Déficit de Atenção, 2016)

Segundo Silva, 2014, uma alimentação adequada / equilibrada a partir de amidos de lenta digestão e por cereais integrais, evitando alimentos processados, refinados, gorduras hidrogenadas, pode produzir efeitos consideráveis a saúde do

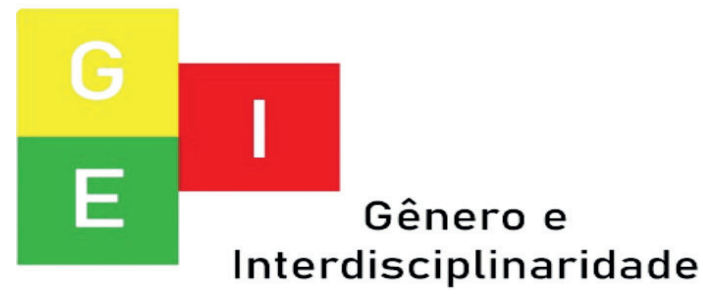


ISSN: 2675-7451

Vol. 02 - n 05 - ano 2021

Editora Acadêmica Periodicojs

cérebro; a pratica de atividades

físicas que gere dopamina, ou atividades aeróbicas como a caminhada, natação ou andar de bicicleta é sempre bem vinda para os TDAs; a ingestão de água é muito importante para a circulação sanguínea, pois tudo o que faz bem para a saúde física, também é bom para o cérebro, pois é ele quem comanda todas as funções do nosso corpo.

O PAPEL DA FAMÍLIA E DA ESCOLA

CONTRIBUIÇÃO DA FAMÍLIA

Como diz o ditado popular "saber é poder" - para a família quanto mais informações tiverem para reconhecer / compreender os sintomas TDA, mais ferramentas emocionais terão para lidar com as situações que surgirem, pois de acordo com Silva (2014, p. 82) "o passo inicial para todos os pais e/ou cuidadores é o conhecimento. Quanto mais estudarem, se informarem e se educarem sobre o problema de seus filhos, mais estarão preparados para lidar com eles de forma apropriada."

A Bíblia o livro dos cristãos também nos fala da importância da busca do conhecimento para tudo na vida: "Feliz é o homem que acha sabedoria, e o homem que adquire conhecimento; porque melhor é o lucro que ela dá do que o da prata, e melhor sua renda do que o ouro mais fino.” (BÍBLIA, Provérbios

Para que seu filho tenha sucesso na vida escolar é importante a comunicação regular entre família e escola, ambos devem andar de mãos dadas para o bom desempenho acadêmico e

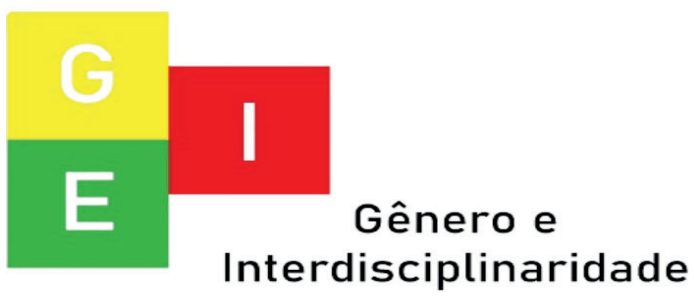


ISSN: 2675-7451

Vol. 02 - n 05- ano 2021

Editora Acadêmica Periodicojs

emocional da criança.

Esteja em contato com os professores de seu filho regularmente, mas você também deve estar sempre em contato com os diretores da escola para determinadas questões. Determine quem serão os seus contatos regulares quanto ao ensino, e como você irá se comunicar com eles, seja por telefone, e-mail, torpedos ou através do caderno de tarefas de casa. Você terá que abrir canais de comunicação para manter-se informada sobre quaisquer questões relacionadas com seu filho e agir com prontidão para qualquer eventualidade. (STEVENS, STONE, McNALLY, 2012, p. 136)

Crianças TDAHs podem padecer com baixa autoestima e terem problemas nas relações interpessoais, algumas enfrentam o bullying e a exclusão por não ajustar-se nos padrões esperados, por isso, "mostre sempre quanto você a ama e quanto fica feliz diante de cada pequena coisa que ela consegue fazer. Ela se esforçará para agradar aos pais e/ou cuidadores, e aos poucos passará a recuperar sua autoconfiança ou a construir a que nunca teve. (SILVA, 2014, p. 87)

\section{CONTRIBUIÇÃO DA ESCO-}

\section{LA}

Nesse tópico iremos falar sobre o papel da escola e a relação professor e aluno, pois a escola é uma forte influencia de socialização em uma comunidade, vamos falar das qualidades que o professor precisa ter para que a comunicação entre ele e o

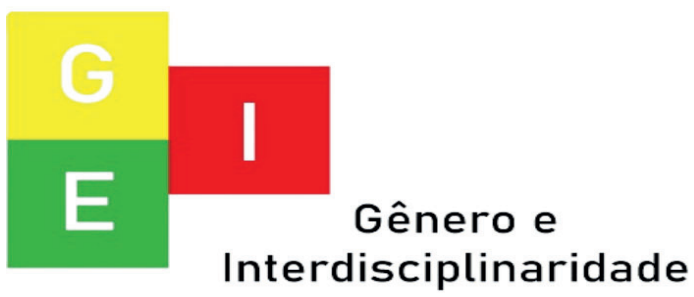


ISSN: 2675-7451

Vol. 02 - n 05 - ano 2021

Editora Acadêmica Periodicojs

aluno seja eficiente e dessa forma ocorra aprendizagem significativa, pois, conforme ABDA - Associação Brasileira do Déficit de Atenção (2016) “devido à baixa concentração de dopamina e/ou noradrenalina, leva o indivíduo a uma tríade sintomatológica de falta de atenção, hiperatividade e impulsividade, ocasionando sérias dificuldades para o processo de aprendizagem".

Como vimos às crianças TDAHs tem dificuldades de aprendizagens, o que o professor pode fazer para ajudar seus alunos com este transtorno nesse processo? Silva (2014, p. 90) sugere que: "professores devem ter conhecimento sobre o assunto, jogo de cintura e flexibilidade para ajudar o aluno TDAH. A informação é o passo mais importante para entender como funciona a cabeça dessas crianças."
De acordo com Phelan (2005), alguns médicos prescrevem medicamentos para o período da escola, isso quer dizer que o único observador dos efeitos da medicação é o professor, e para o sucesso do tratamento as observações tanto positivas, quanto negativas, devem ser comunicadas aos pais e ao médico. Também é importante os professores saberem como esses estimulantes atuam, para terem noção do que se pode esperar dos efeitos desses e em quanto tempo começam a surtir efeito, pois não é preciso aguardar um mês, de três a cinco dias já dá para ter noção se o tratamento está surtindo efeito ou não. Sabemos que os professores não prescrevem remédios, mas essas observações são fundamentais para o sucesso do aluno TDAH.

Os professores também

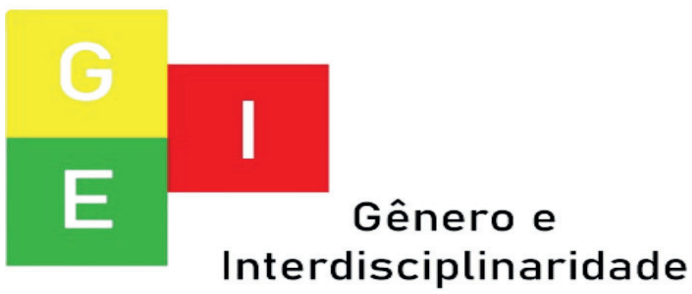


Vol. 02 - n 05 - ano 2021

Editora Acadêmica Periodicojs

poderão ajudar o aluno TDAH, reconhecendo as coisas que ele sabe fazer, elogiando-o, reforçando o que ele faz bem feito, tendo empatia por ele.

A criança TDA pode dar tudo de si e deixar fluir sua criatividade e seu entusiasmo inatos se for corretamente estimulada. Mais do que qualquer outra, a criança TDA responde maravilhosamente bem ao calor do incentivo. Os elogios e as recompensas constantes se constituem no melhor aditivo para a grande quantidade de combustível da qual foi dotada. (SILVA, 2014, p. 74)

Ao falarmos sobre aprendizagem, é fundamental ter em conta que a afetividade atua associadamente nesse processo.

É consenso entre os pesquisadores e te- óricos da Educação

que os sentidos e a emoção são componentes importantíssimos no contexto da aprendizagem. Esta importância se traduz no processo de armazenamento de informações, ou seja, na memorização de conteúdos ministrados na escola e de eventos significativos ocorridos no cotidiano social do aprendiz. (BARRETO, 2014, p. 1220)

Os professores precisam ser afetuosos, amigáveis e cordiais, pois desejam o melhor para seus alunos, "por isso, o educador ou a educadora - aqueles (as) que lidamos com o futuro, que lidamos com a Educação que nos transporta a um novo tempo, no qual se deseja uma melhor condição de existência, em que a vitalidade, a dignidade e a frater-

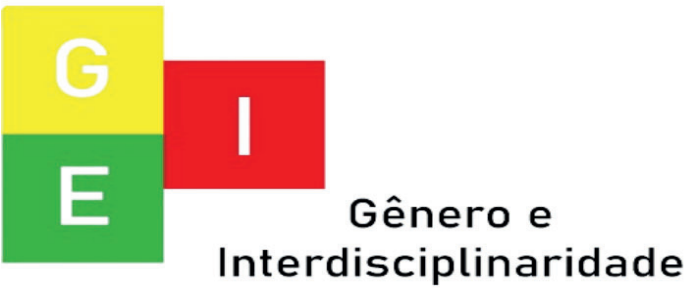


ISSN: $2675-7451$

Vol. 02 - n 05- ano 2021

Editora Acadêmica Periodicojs

nidade têm lugar." (CORTELLA, 2014, p. 37)

Os princípios e hábitos do professor devem ser considerados de maior importância do que mesmo suas habilidades literárias. Se o professor é cristão sincero, ele sentirá a necessidade de ter interesse igual na educação física, mental, moral e espiritual de seus alunos. A fim de exercer a influencia devida deve ele ter perfeito controle sobre si mesmo e ter o coração ricamente impregnado de amor pelos alunos, o que se verá em seu olhar, suas palavras e atos. Deve ter a firmeza de caráter; então poderá moldar a mente dos alunos, assim como instruí-los nas ciências. (WHITE, 2014, p. 138)

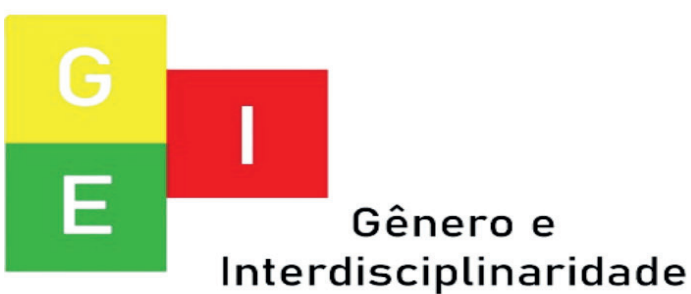

93) destaca,
Sabemos que não existe uma solução simples ou mágica no trato com alunos TDAs e que tudo requer tempo, dedicação e persistência. 
ISSN: 2675-7451

Vol. 02 - n 05 - ano 2021

Editora Acadêmica Periodicojs

Mas, sem sombra de dúvida, o empenho dos pais e dos implicados no bem-estar dos pequenos depende, e muito, do banco escolar. Esses fatores, em conjunto, determinarão $\mathrm{o}$ futuro dessas crianças e carimbarão o passaporte delas rumo a uma vida menos caótica e mais feliz.

\section{LEIS QUE REGEM O DIREI-}

TO A EDUCAÇÃO DESTA NECESSIDADE EDUCACIONAL ESPECIAL E A IMPORTÂNCIA DESTE DIREITO.

De acordo com ABDA Associação Brasileira do Déficit de Atenção o Transtorno do Déficit de Atenção e Hiperatividade é reconhecido oficialmente por vários países e pela Organização Mundial da Saúde (OMS). Em alguns países, como nos Estados
Unidos, portadores de TDAH são protegidos pela lei quanto a receberem tratamento diferenciado na escola. No Brasil ainda não existem políticas públicas oficiais, em âmbito federal, para as pessoas com TDAH. A Política Nacional de Educação Especial na Perspectiva da Educação Inclusiva, lançada pelo Ministério da Educação, no ano de 2007, não incluiu alunos com TDAH como público alvo da Educação Especial, embora o Brasil seja signatário da Organização das Nações Unidas (ONU), e tenha assinado a Declaração de Salamanca documento "Regras Padrões sobre Equalização de Oportunidades para Pessoas com Deficiências", o qual demanda que os Estados assegurem que a educação de pessoas com deficiências seja parte integrante do sistema educacional. Desde então, a Sociedade Civil Organizada, a exemplo

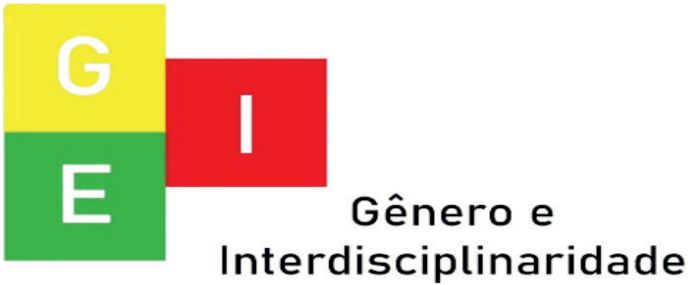


ISSN: 2675-7451

Vol. 02 - n 05 - ano 2021

Editora Acadêmica Periodicojs

da ABDA (Associação Brasileira

do Déficit de Atenção, vem se Concluímos através da mobilizando no sentido de conquistar algumas garantias legais para as pessoas com TDAH. (ABDA - Associação Brasileira do Déficit de Atenção, 2014)

Sabemos que vários profissionais apóiam a ideia de que o TDAH necessita de um programa educacional individualizado / diferenciado, como acontece nos Estados Unidos, "embora haja projetos aprovados pelo senado, as regras e regulamentos ainda não estão em vigência nas escolas públicas brasileiras, mas começam a surgir centros de apoio aos alunos, que oferecem aulas particulares com base no currículo da instituição de ensino regular." (STEVENS, STONE, McNALLY, 2012, p. 46)

CONSIDERAÇÕES FINAIS

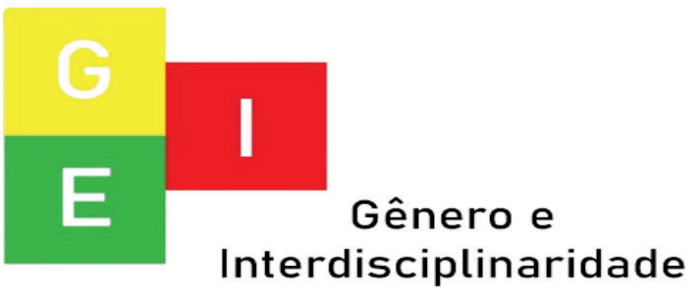
pesquisa realizada que o transtorno do Déficit de atenção é um transtorno neurobiológico de origem genética, que se caracteriza por sintomas de alteração da atenção, Impulsividade e Hiperatividade Física / Mental, e que o ambiente não determina o surgimento deste transtorno, e que também o cérebro TDAH em nada se difere em sua estrutura de um cérebro não TDAH, portanto, não tendo relação com déficit intelectual. A diferença está na atividade química dos neurotransmissores desse cérebro, por isso não ser tão eficiente.

Os tratamentos disponíveis atualmente pra amenizar os sintomas desse transtorno e ajudar seus portadores a desenvolver suas habilidades e assim, melhoras sua auto-estima, são as medicações e a psicoterapia; o 
Vol. 02 - n 05 - ano 2021

Editora Acadêmica Periodicojs

conhecimento, apoio técnico, hábitos de vida saudáveis também são grandes aliados ao tratamento.

A família e a escola tem um papel importante para que a aprendizagem seja significativa, andando juntas para o sucesso na vida acadêmica deste aluno, por isso a comunicação entre ambas precisa ser eficiente.

O professor com seu olhar atento pode auxiliar seu aluno TDAH em seu processo de aprendizagem tendo uma conduta amorosa pois a aprendizagem e afetividade atuam associadamente.

O Transtorno do Déficit de Atenção e Hiperatividade é reconhecido oficialmente pela Organização Mundial da Saúde (OMS) e por diversos países, também está no Manual diagnóstico e estatístico de transtornos mentais: DSM-5, e apesar de haver um consenso entre os profissionais de que necessita de um programa individualizado, infelizmente no Brasil ainda não existem leis específicas em âmbito federal, para alunos com esse transtorno.

\section{REFERÊNCIAS}

ABDA - Associação Brasileira do Déficit de Atenção. O que é TDAH. 07/12/2010. Disponível em: <https://tdah.org.br/o-que-e-o-tdah/>. Acesso em 30/09/20.

ABDA - Associação Brasileira do Déficit de Atenção. TDAH e o processo de aprendizagem. 08/06/2016. Disponível em: $<$ https://tdah.org.br/tdah-e-o-processo-de-aprendizagem/>. Acesso em 30/09/20.

ABDA - Associação Brasileira do Déficit de Atenção . Enten-

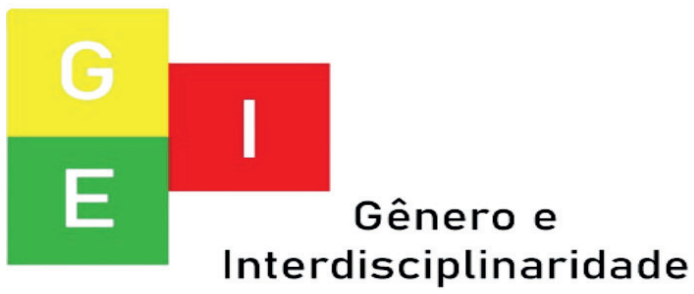


ISSN: $2675-7451$

Vol. 02 - n 05 - ano 2021

Editora Acadêmica Periodicojs

da o funcionamento da legisla-

ção brasileira sobre o TDAH.

08/10/2014. Disponível em: <ht-

tps://tdah.org.br/entendo-o-fun-

cionamento-da-legislacao-brasi-

leira-sobre- o-tdah/>. Acesso em

$30 / 09 / 20$.

BARRETO, Flávio Chame. Es-

tratégias Docentes Eficazes:

Quando a Neurociência, as Teo-

rias de Aprendizagem e a Prática

do Professor se complementam.

Rio de Janeiro, 2014. Edição do

Kindle.

BÍBLIA, Português. Bíblia Sagrada. Tradução: Almeida Revista e Atualizada. Barueri: Sociedade Bíblica do Brasil, 2007.

BÍBLIA, Português. Bíblia Sagrada. Tradução: Nova Tradução na Linguagem de Hoje. Barueri: Sociedade Bíblica do Brasil, 2000.
CORTELLA, Mario Sergio. Educação, escola e docência: novos tempos, novas atitudes. São Paulo: Cortez, 2014.

\section{AMERICAN PSYCHIATRIC} ASSOCIATION. DSM-5: manual diagnóstico e estatístico de transtornos mentais. 5. ed. [recurso eletrônico]. Porto Alegre: Artmed, 2014. 992p.

PHELAN, Thomas W. TDA/ TDAH - Transtorno de Déficit de Atenção e Hiperatividade: Sintomas, Diagnósticos e Tratamento, Crianças e Adultos. São Paulo: M. Books do Brasil Editora Ltda., 2005.

SILVA, Ana Beatriz Barbosa. Mentes Inquietas: TDAH: desatenção, hiperatividade e impulsividade. São Paulo: Globo, 2014.

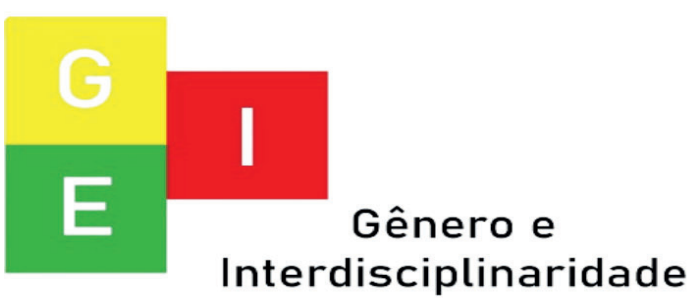


ISSN: 2675-7451

Vol. 02 - n 05 - ano 2021

Editora Acadêmica Periodicojs

STEVENS, Annabelle; STONE,

Carolyn; McNALLY, Siobhan.

Estratégias de sucesso na esco-

la para crianças com o TDAH.

New York: Eternal Spiral Books,

2012. http://EternalSpiralBooks.

com. Edição do Kindle.

WHITE, Ellen G. Mente, caráter e personalidade: guia para a saúde mental e espiritual. Tatuí: Casa Publicadora Brasileira, 2014.

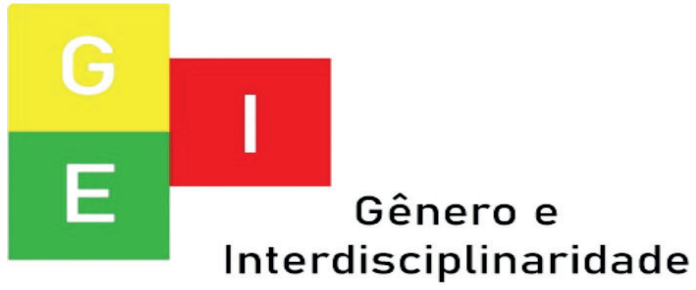

